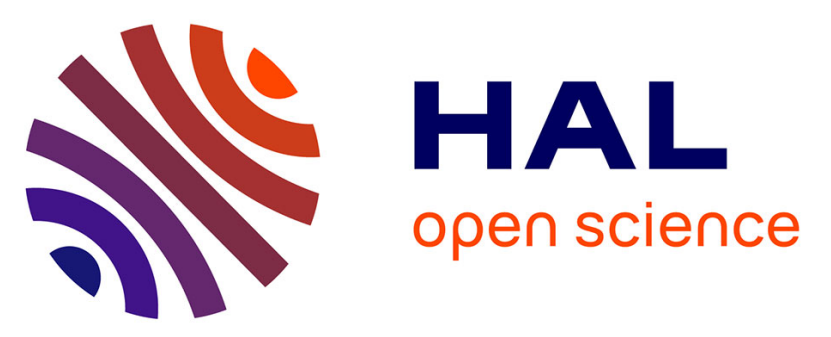

\title{
Come to light: Detailed analysis of thermally treated Phenyl modified Carbon Nitride Polymorphs for bright phosphors in lighting applications
}

Stefania Porcu, Ignazio Roppolo, Mathieu Salaün, Giorgia Sarais, Simone Barbarossa, Maria Francesca Casula, Carlo Maria Carbonaro, Pier Carlo Ricci

\section{- To cite this version:}

Stefania Porcu, Ignazio Roppolo, Mathieu Salaün, Giorgia Sarais, Simone Barbarossa, et al.. Come to light: Detailed analysis of thermally treated Phenyl modified Carbon Nitride Polymorphs for bright phosphors in lighting applications. Applied Surface Science, 2020, 504, pp.144330. 10.1016/j.apsusc.2019.144330 . hal-02565038

\section{HAL Id: hal-02565038 \\ https://hal.science/hal-02565038}

Submitted on 12 May 2020

HAL is a multi-disciplinary open access archive for the deposit and dissemination of scientific research documents, whether they are published or not. The documents may come from teaching and research institutions in France or abroad, or from public or private research centers.
L'archive ouverte pluridisciplinaire HAL, est destinée au dépôt et à la diffusion de documents scientifiques de niveau recherche, publiés ou non, émanant des établissements d'enseignement et de recherche français ou étrangers, des laboratoires publics ou privés. 
Full Length Article

\title{
Come to light: Detailed analysis of thermally treated Phenyl modified Carbon Nitride Polymorphs for bright phosphors in lighting applications
}

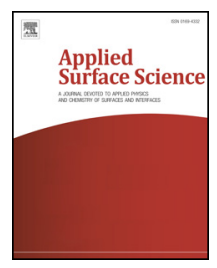

\author{
Stefania Porcu ${ }^{\mathrm{a}}$, Ignazio Roppolo ${ }^{\mathrm{b}}$, Mathieu Salaun ${ }^{\mathrm{c}}$, Giorgia Sarais ${ }^{\mathrm{d}}$, Simone Barbarossa ${ }^{\mathrm{e}}$, \\ Maria Francesca Casula ${ }^{\mathrm{e}}$, Carlo Maria Carbonaro ${ }^{\mathrm{a}}$, Pier Carlo Ricci ${ }^{\mathrm{a}, *}$ \\ ${ }^{\text {a }}$ Department of Physics, University of Cagliari, S.p. no. $8 \mathrm{Km} \mathrm{0700,09042} \mathrm{Monserrato,} \mathrm{CA,} \mathrm{Italy}$ \\ ${ }^{\mathrm{b}}$ Department of Applied Science and Technology, Politecnico di Torino, Corso Duca degli Abruzzi 24, Torino 10129, Italy \\ ${ }^{\mathrm{c}}$ Univ. Grenoble Alpes, Inst NEEL, F-38042 Grenoble, France \\ d Department of Life and Environmental Sciences, University of Cagliari, Via Ospedale 72, 09124 Cagliari, Italy \\ ${ }^{\mathrm{e}}$ Department of Mechanical, Chemical, and Materials Engineering INSTM, University of Cagliari, Via Marengo, 3, 09123 Cagliari, Italy
}

\section{A R T I C L E I N F O}

\section{Keywords:}

Carbon Nitride

g- $\mathrm{C}_{3} \mathrm{~N}_{4}$

Polymers

Lighting materials

\begin{abstract}
A B S T R A C T
Carbon Nitride and its polymorphs have recently gained large interests for their huge properties and applications in different fields, from lighting to photocatalysis. Further, several attempts were recently devoted to tune and control its optical and electrical properties. In this report we analyze phenyl modified Carbon Nitride structures obtained by simple thermal polymerization at different temperatures $\left(250-400{ }^{\circ} \mathrm{C}\right)$ of the starting precursor: 2 ,4diamino-6-phenyl-1,3,5-triazine. A multi-technique experimental data (XRD patterns, Raman, TGA and DTG, steady- time and time resolved Luminescence, Photoluminescence Excitation spectra, Reflectivity spectra) was applied to analyze the relationship between structural and optical properties and to give more insight on the effect of synthesis procedure on the final polymer. The optical properties evidenced an interesting shift towards the visible region of the absorption spectrum of the phenyl modified $\mathrm{g}-\mathrm{C}_{3} \mathrm{~N}_{4}$ polymer that, associated with the high optical quantum yield (about 60\%) and to a broad emission in the green-red spectral region, makes the samples very suitable for lighting applications. Indeed, we report a first prototype of white LED emission by assembly of a commercial blue LED and the Phenyl modified $\mathrm{g}-\mathrm{C}_{3} \mathrm{~N}_{4}$ powders as phosphor, verifying the structural and optical stability over about 10,000 working hours.
\end{abstract}

\section{Introduction}

Nowadays, research in new materials is instrumental to reach a sustainable, energy saving and eco-friendly development. New materials for lighting, catalysis and photocatalysis, photovoltaic and water splitting are of paramount importance for "next future" technologies; however, their application should be subjected to sustainable life-cycle assessment, too often not considered since the inception. Materials with very expensive synthesis procedures, both in terms of costs and/or energy consumption, as well as potentially eligible to produce dangerous or polluting waste need to be discarded. In this view, materials free of "critical" raw elements are very attractive and the research in this direction is boosted, looking for available alternatives, among which the most promising are new organic materials [1-3].

Within the organic chemistry panorama, polymers can guarantee very high versatility in terms of structural and optical response with high potential in several applications, from electronics to photovoltaics
[4-6], but their efficient exploitation in commercial devices is hampered by the low thermal and short time structural stability of the compounds.

Since 2014, an increasing attention has been devoted to graphitic Carbon Nitride $\left(\mathrm{g}-\mathrm{C}_{3} \mathrm{~N}_{4}\right)$ defined as one of most reliable photocatalysts for artificial photosynthesis and pollution degradation [7]. It was indicated as a very promising material for photovoltaic applications [8], a very efficient phosphor for lighting applications, $[9,10]$ and lastly as a suitable photocatalysts for hydrogen generation, [11] and water splitting [12].

Most of its high-ranking properties are related to its thermal and structural stability, taking advantage with its simply and low-cost synthesis procedure. $\mathrm{g}-\mathrm{C}_{3} \mathrm{~N}_{4}$ is fabricated by direct condensation of nitrogen-containing organic precursors (for example, urea, thiourea, dicyandiamide, cyanamide, and guanidine hydrochloride) [13,14]. Recently, g- $\mathrm{C}_{3} \mathrm{~N}_{4}$ structure with thermal stability up to $550{ }^{\circ} \mathrm{C}$ was successfully obtained by direct condensation of melamine [15], leading

\footnotetext{
* Corresponding author.

E-mail address: carlo.ricci@dsf.unica.it (P.C. Ricci).
} 
to the formation of different polymorphs depending on the synthesis temperature [16].

Depending on the above-mentioned synthesis procedures, different optical properties were reported [17-19]. The possibility to tune the optical properties of carbon nitride based materials was largely explored, by doping with specific elements (among others $\mathrm{Fe}, \mathrm{Ag}, \mathrm{Br}, \mathrm{P}$, $\mathrm{Br}, \mathrm{I})$ [20-23] or by slightly changing the organic mesh [24]. In this scenario, recently doping with phenyl ring was applied $[17,25]$, because of the promising results in tuning the band-gap of the organic semiconductor to lower energies. Indeed, the introduction of phenyl groups into the melon frame extends the $\pi$-conjugation in g- $\mathrm{C}_{3} \mathrm{~N}_{4}$, leading to a decrease of the band gap and to an increase of the separation rate of electron-hole pairs [17]. To achieve the doped mesh, the strategy of election was a co-polymerization process of benzamide and urea $[17,28]$. Alternatively, a solvent free thermal treatment at $400{ }^{\circ} \mathrm{C}$ of a single precursor, 2,4-diamino-6-phenyl-1,3,5-triazine was successfully applied [26].

This last strategy seems very promising to produce sustainable materials: the solvent free reaction, the absence of metals and critical raw materials, the low cost of the starting precursor are fundamental parameters for the development of new green materials. However, a step by step study on the relationship between thermal synthesis, structural characterization and application/performance was never performed on this new class of Carbon Nitride materials.

In this paper we report structural and optical characterization of phenyl modified g- $\mathrm{C}_{3} \mathrm{~N}_{4}$ samples (hereafter PhCN) grown in controlled atmosphere at different temperature starting from 2,4-diamino-6phenyl-1,3,5-triazine as precursor, without the use of any solvent. We applied a multi-techniques approach, which improves the predictive process, providing deep insights on the correlation among optical features, morphology and effective structure of the carbon nitride polymers. This opens the possibility to tune the properties of phenyl modified organic meshes for further technological exploitations. To test the bench strength, we provided a direct application of the phenyl modified structure for lighting. A first prototype of white LED is achieved by modifying a commercial Blue LED with one of the phosphors here described. The stability in time, the efficiency and the color rendering index are reported to provide a wide characterization and to suggest this class of organic compound as an efficient phosphor for lighting applications.

\section{Experimental}

\subsection{Materials and methods}

$1 \mathrm{~g}$ of 6-phenyl-1,3,5-triazine-2,4-diamine powder (Ph-Triazine, Aldrich, 99\%) was placed in a quartz tube accommodated in a tubular furnace and treated at different temperatures $\left(250^{\circ} \mathrm{C}, 300^{\circ} \mathrm{C}, 350^{\circ} \mathrm{C}\right.$ and $400^{\circ} \mathrm{C}$ ) for $1 \mathrm{~h}$ (hereafter PhCN250, PhCN300, PhCN350 and PhCN400, respectively). The samples during the thermal treatment were covered with a quartz plate to prevent the vaporization at high temperature and to assure a re-condensation at high temperature. The heating rate was $30^{\circ} \mathrm{C} / \mathrm{min}$, the syntheses were performed under constant nitrogen flux $(30 \mathrm{ml} / \mathrm{min})$. All samples were manually grounded to obtain powder-like samples and washed with methanol several times to remove the impurities.

\subsection{Characterization techniques}

X-Ray Diffraction measurements were made by using a Malver Panalytical Empyrean Diffractometer with $2 \theta$ Bragg-Brentano geometry, $\mathrm{Cu}$ Ka wavelength and X'Celerator silicon detector which uses a RTMS (Real Time Multiple Strip) 1D acquisition technology.

Raman spectra were acquired in back scattering geometry with excitation wavelength at $1064 \mathrm{~nm}$ generated by a Nd:YAG laser, to avoid luminescence contribution in the visible range. The system operates in Stokes region up to $2500 \mathrm{~cm}^{-1}$. Measurements were performed in air at room temperature with a spectrometer BWTEK i-Raman ex with a spectral resolution of a $9 \mathrm{~cm}^{-1}$.

Elemental analysis was performed on the dry samples by a PerkinElmer 24,000 Series II CHN Analyzer.

High Resolution Mass Spectra (HRMS) of products were obtained using a High-Resolution Mass Spectrometer in fast atom bombardment $(\mathrm{FAB}+)$ ionization mode (ESI) acquired using a Bruker micrOTF-Q II or/and Agilent Q-TOF 6520.

Thermo-gravimetric analysis (TGA) was performed with Netzch 209 F1 Libra. The samples were heated from $25^{\circ} \mathrm{C}$ to $800^{\circ} \mathrm{C}$ (heating rate $10^{\circ} \mathrm{C} / \mathrm{min}$ ) under constant nitrogen flux $(20 \mathrm{ml} / \mathrm{min})$. The same equipment was used for the on-line monitoring of the reaction, coupling the instrument to a BRUKER Optics FTIR. In this case, the synthesis procedure was simulated in the TGA (heating ramp from $20^{\circ} \mathrm{C}$ to $400{ }^{\circ} \mathrm{C}$ with a rate of $20^{\circ} \mathrm{C} / \mathrm{min}$ followed by an isothermal step at $400{ }^{\circ} \mathrm{C}$ of $1 \mathrm{~h}$, nitrogen flow $20 \mathrm{ml} / \mathrm{min}$ ). Data exchange between NETZSCH PROTEUS software and Bruker OPUS software is done online during the measurement. The gases that evolved by thermal analysis are transferred into the IR spectrometer from Bruker Optics and analyzed with a Bruker Tensor2 FT-IR. The gas cell is heated to $200^{\circ} \mathrm{C}$ and possesses a volume of $5.8 \mathrm{ml}$. IR -scanned range was from $400 \mathrm{~cm}^{-1}$ to $5000 \mathrm{~cm}^{-1}$. Every spectrum is averaged from 16 scans.

Differential Scanning Calorimetry (DSC) measurements were acquired by using DSC1 METTLER STAR1 System equipped with a low temperature probe. The measurements were performed in nitrogen atmosphere. For all the samples, the thermal cycle was: isothermal step for $5 \mathrm{~min}$ at $-30^{\circ} \mathrm{C}$, heating from $-30^{\circ} \mathrm{C}$ to $250^{\circ} \mathrm{C}$ then cooling from $250{ }^{\circ} \mathrm{C}$ to $-30{ }^{\circ} \mathrm{C}$, registering a second isotherm at $-30{ }^{\circ} \mathrm{C}$ for $5 \mathrm{~min}$ and heating again with the same heating ramp. The second thermogram was discussed in the text.

The absorption measurements were acquired by a UV-Vis-NIR Agilent Technologies Cary 5000. Measurements were performed by using a $\mathrm{PbS}$ solid state photodetector. The reflection configuration measures the diffuse reflection of a sample with respect to a reference sample which is considered to have a $100 \%$ reflectivity.

Steady-state photoluminescence measurements were performed with a $405 \mathrm{~nm}$ laser excitation coupled with an optical fiber to an Avantes Sensilne Avaspec-ULS-TEC Spectrometer. The measurements were acquired with $500 \mathrm{~ms}$ time window in a $300-800 \mathrm{~nm}$ spectral range.

Time resolved photoluminescence (TR-PL) measurements were recorded by exciting the samples with $200 \mathrm{fs}$ long pulses delivered by an optical parametric amplifier (Light Conversion TOPAS-C) pumped by a regenerative Ti:sapphire amplifier (Coherent Libra-HE). The repetition frequency was $1 \mathrm{kHz}$ and the PL signal was recovered by a streak camera (Hamamatsu C10910) equipped with a grating spectrometer (Princeton Instruments Acton SpectraPro SP-2300). All the measurements were collected in the front face configuration to reduce inner filter effects. Proper emission filters were applied to remove the reflected contribution of the excitation light.

The luminescence quantum yield was measured using a 10-inch diameter integrating sphere (Lab sphere, LMS-100) and a $385 \mathrm{~nm}$ LED (ThorLabs) for excitation and the signals were recorded using a CCD detector (Ocean optics, USB4000-VIS-NIR). The spectral intensity calibration was carried out using a standard Deuterium-Tungsten Halogen lamp (Ocean Optics, DH-3P-BAL-CAL). The sample was dispersed in a $1 \mathrm{~mm}$ thick PDMS pellet before placing inside the integrating sphere. The signals were recorded by placing the sample in-line with the excitation beam and for reference, the base support was placed in-line with the excitation beam. The internal quantum yield was measured by comparing the emitted photons with respect to absorbed photons. In order to validate the obtained values, the internal quantum yield of a YAG:Ce standard phosphor from OSRAM, Inc., was measured under $440 \mathrm{~nm}$ LED excitation using the same set-up and is found to be about $60 \%$ in place of $82 \%$, which lead to apply a correction factor of. The 


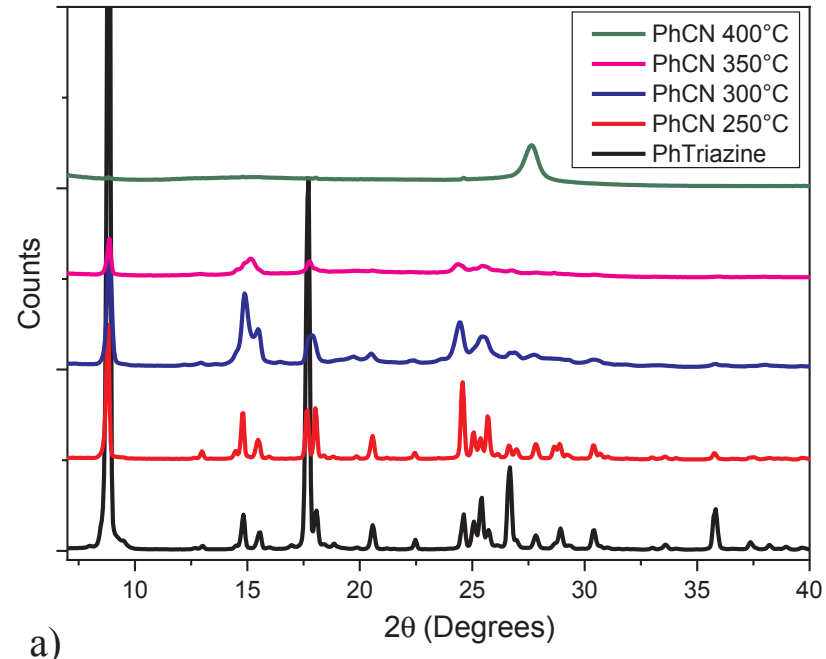

a)

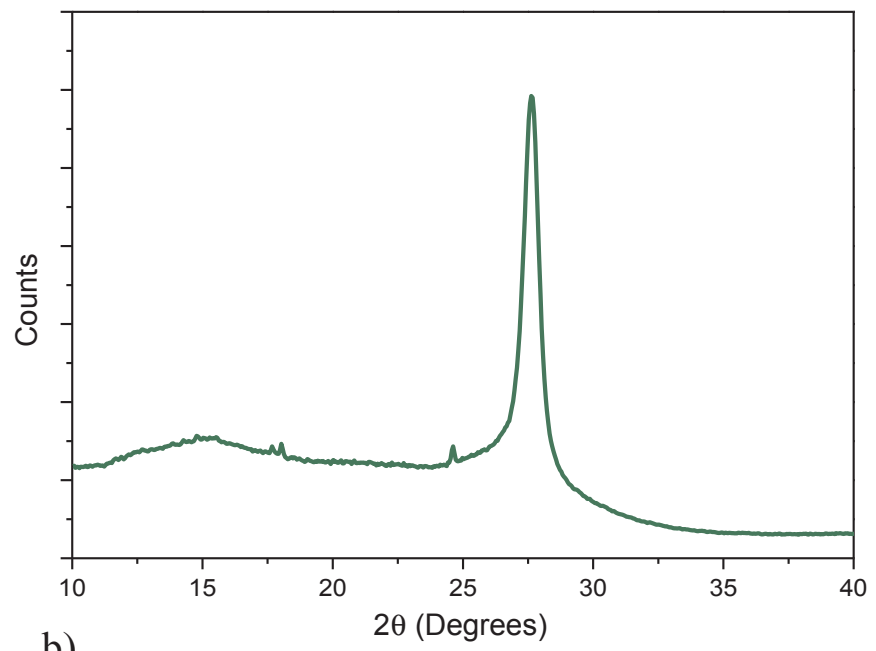

b)

Fig. 1. (a) X-Ray diffraction patterns of the samples obtained at different temperature starting from the precursor (6-phenyl-1,3,5-triazine-2,4-diamine). (b) X-Ray diffraction pattern of the sample prepared at $400{ }^{\circ} \mathrm{C}$.

total uncertainty in YAG:Ce quantum yield is up to $10 \%$, which suggests an uncertainty of more than $10 \%$ in the quantum yield of a-YAB powders measured under near UV excitation.

\section{Results and discussions}

\subsection{Structural properties}

\subsubsection{X-Ray diffraction measurements}

To show how thermal treatment affects the final structure of the polymer, we report X-Ray diffraction patterns of the PhCN samples treated at different temperature obtained from $\mathrm{Ph}$-Triazine precursor (Fig. 1a and b).

The plots display well defined diffraction peaks at $8.8^{\circ}, 17.7^{\circ}, 24.5^{\circ}$, $25.3^{\circ}, 26.6^{\circ}$ and $35.8^{\circ}$ in 29 , denoting a semi-crystalline structure. PhCN250 sample exhibits a reduction in the intensity of the main peaks at $8.8^{\circ}, 17.7^{\circ}, 26.6^{\circ}$ and $35.8^{\circ}$ and a variation in the intensity ratio in the $24.5-25.3^{\circ}$ range without any further clear modification in the profile. Increasing the synthesis temperature up to $300^{\circ} \mathrm{C}$, it is possible to observe a broadening in all the diffraction peaks, with the overlapping of most of them. An overall reduction of the peaks counts with variation in the relative intensities among the diffraction peaks is observable for the pattern of the sample PhCN350. Finally, an abrupt variation is clearly detected in the pattern of the sample prepared at $400{ }^{\circ} \mathrm{C}$, where, as already reported [19], only two broad bands, located at about $15^{\circ}$ and $27.6^{\circ}$, can be distinguished. Considering the high similarity with the XRD diffraction pattern of undoped Carbon Nitride, the peak located at higher angles is assigned to $\left(\begin{array}{lll}0 & 0 & 1\end{array}\right)$ reflection and it is related to the distance among planes whilst the one at $15^{\circ}$ and is associated to the reflection from (210) plane and it is related to the separation distance of heptazine chains [27].

In $\mathrm{g}-\mathrm{C}_{3} \mathrm{~N}_{4}$ the higher angle diffraction peak was reported at $27.3^{\circ}$ and $27.5^{\circ}$ for the Carbon nitride samples treated at 500 and $600{ }^{\circ} \mathrm{C}$, respectively [16] (slightly variations of these values were also reported, depending on minor changes in synthesis procedure) $[28,29]$. The observed peaks in the PhCN400 sample indicates that the general 2D structure of the $\mathrm{g}-\mathrm{C}_{3} \mathrm{~N}_{4}$ is preserved but, with a smaller distance among the planes (from $3.26 \AA$ to $3.24 \AA$ in $g-\mathrm{C}_{3} \mathrm{~N}_{4}$ ). The broad diffraction peak at lower angles, with main features at about $13^{\circ}$ and 15 in the PHCN400 diffraction pattern $\left(13.2^{\circ}\right.$ in $\left.\mathrm{g}-\mathrm{C}_{3} \mathrm{~N}_{4}\right)$ indicates a broad distribution of the separation distance among the heptazine chains in each plane (see in Fig. 1b the magnification of the XRD pattern of PhCN400 sample). In view of optical features, one has to bear in mind that a shortening in the inter-plane distance is the main cause of emission quenching in Carbon nitride samples $[16,30]$. However, as we will better explain in the optical section, in the PhCN400 sample we observe a very high increase of the optical quantum yield with respect to $\mathrm{g}-\mathrm{C}_{3} \mathrm{~N}_{4}$, that underline the key role of the phenyl rings in the heptazine mesh.

\subsubsection{Raman analysis}

The Raman spectra give information on the structure of the polymorphs (Fig. 2a). The spectrum of the phenyl-triazine presents several bands between 200 and $1600 \mathrm{~cm}^{-1}$, with prominent peaks at $1601 \mathrm{~cm}^{-1}$, related to the motion of the phenyl group, and at $1392 \mathrm{~cm}^{-1}$, assigned to conjugated stretching vibration (C-C) between the phenyl ring and the triazine ring [31]. Other prominent figures are at $1000 \mathrm{~cm}^{-1}$ (breathing mode) and $674 \mathrm{~cm}^{-1}$, related to $\mathrm{NH}_{2}$ modes (Fig. S1-a). The spectra of the samples treated at different temperatures present slight variation in the peaks position. The main change is gathered in the relative contribution of the Raman peaks, enlightened by comparing the intensities at 1392 and $1601 \mathrm{~cm}^{-1}$ (Fig. 2b). The ratio $\mathrm{I}_{1600 / 1390}$ value (about 1 ) keeps constant up to $250^{\circ} \mathrm{C}$ then it increases to 1.34 , at $300{ }^{\circ} \mathrm{C}$, and to 1.57 at $350^{\circ} \mathrm{C}$. Finally, an abrupt increase up to 3.54 is observed in the sample treated at $400^{\circ} \mathrm{C}$.

This trend can be understood by analyzing deeply the vibration modes: since the band at $1392 \mathrm{~cm}^{-1}$ is related to the conjugated motion of the triazine and the phenyl ring through the stretching mode of the $\mathrm{C}-\mathrm{C}$ bonding, a decrease of the vibration intensity is expected when increasing the mass structure of at least one of the two units. Thus, the increase of the ratio with respect to the breathing mode of the phenyl ring suggests the formation of different polymorphs, until the formation of the heptazine units at $400^{\circ} \mathrm{C}$ is achieved.

\subsubsection{Elemental analysis}

The formation of different polymorphs is confirmed by elemental analysis of the compounds; the $\mathrm{C} / \mathrm{N}$ molar ratio spans from 1.54 for the phenyl-triazine precursor down to 1.50 in the sample treated at $300{ }^{\circ} \mathrm{C}$ (PhCN300). Finally, a drastic decrease of the $\mathrm{C} / \mathrm{N}$ molar ratio to 1,24 was measured for the sample prepared at $400{ }^{\circ} \mathrm{C}(\mathrm{S} 2$-Table S1) an indication of the increase of the polymerization degree.

\subsubsection{HRMS analysis}

To better understand the polymerization process and to identify the structure of the intermediate products, high resolution mass spectrometry (HRMS) analysis was carried out. As previously observed in the XRD and Raman analysis, no variations are observed for the sample heated at $250{ }^{\circ} \mathrm{C}$ with respect to the starting Phenyl-Triazine. At $300{ }^{\circ} \mathrm{C}$ the partial formation of the dimer by linear polymerization is indicated 
a)

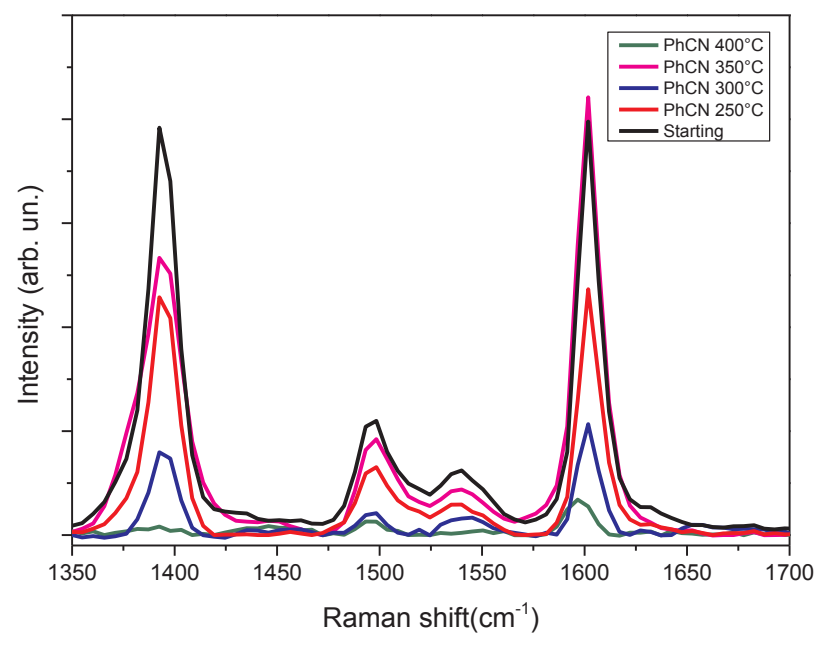

b)

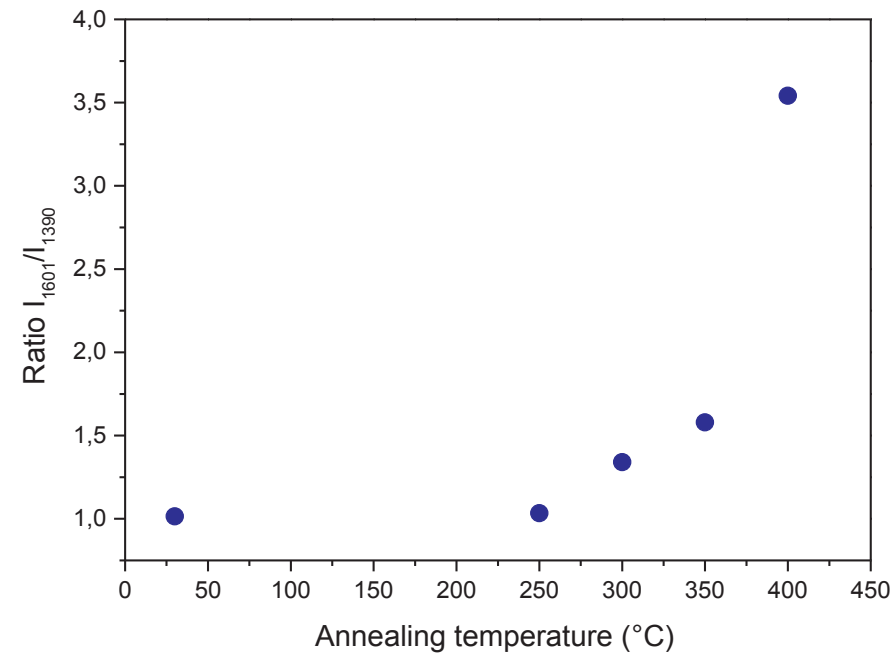

Fig. 2. (a) Raman spectra behavior of the temperature treated samples. (b) Ratio of intensities $\mathrm{I}_{1601} / \mathrm{I}_{1390}$.

by the peak at $358\left(\mathrm{mZ}^{-1}\right)$, this process is further evidenced increasing the curing temperature to $350{ }^{\circ} \mathrm{C}$, where the formation of trimer units at $528\left(\mathrm{mZ}^{-1}\right)$ are also evidenced (Fig. S3). According to the previous analysis, the sample treated at $400{ }^{\circ} \mathrm{C}$ was expected to give rise to the formation of the heptazinic system, but due to its very poor solubility in several solvents, it was not possible to analyze the product.

\subsubsection{Thermogravimetric analysis}

Thermogravimetric (TGA) and Differential Scanning Calorimetry (DSC) measurements confirm that different structures of phenyl modified carbon nitride were obtained. Fig. 3a reports TGA curves measured for the samples cured at different temperatures (PhCN300, PhCN350, PhCN400 and Ph-Triazine). The analysis suggests a rather different volatilization process for the different samples. The Ph-Triazine shows an immediate and almost complete volatilization at temperatures lower than $300{ }^{\circ} \mathrm{C}$. A similar behavior is present both in PhCN300 and in PhCN350 whilst PhCN400 shows a completely different degradation mechanism. More considerations could be done considering DTG curves (Fig. S4 in supporting Information files). As above mentioned, PhTriazine presents a single volatilization peak at $280^{\circ} \mathrm{C}$. Similarly, PhCN300 and PhCN350 samples present a major degradation peak at the same temperature. Moreover, in those samples other degradation peaks at higher temperatures appear $\left(320^{\circ} \mathrm{C}, 460^{\circ} \mathrm{C}\right.$ and then $580^{\circ} \mathrm{C}$ only in PhCN350). This is consistent with an increase of molecular weight in the samples, in good agreement with all the other experiments performed that showed the formation of dimer, trimer, or larger aggregates (i.e. compounds with larger molecular weight). Interestingly, the higher the temperature of pre-treatment, the less important is the degradation peak at lower temperature. In fact, PhCN400 shows the lowest peak (in terms of integrated intensity) at temperatures lower than $300^{\circ} \mathrm{C}$. Regarding the other degradation peaks, in PhCN $400^{\circ} \mathrm{C}$ DTG curve is present a shoulder at $380^{\circ} \mathrm{C}$, indicating the presence of low temperature polymorphs. Moreover, new peaks appear, with a maximum of degradation rate at $660^{\circ} \mathrm{C}$. In good agreement with the diffraction analysis, the appearance of signals at elevated temperatures are related to graphitic structure, and in general to large molecular units. The formation of heptazine ring is further suggested by the comparison with the DTG analysis of pure graphitic Carbon nitride samples, where degradation signals were observed at $380{ }^{\circ} \mathrm{C}$ and $590{ }^{\circ} \mathrm{C}$ [32]. Finally, changing from inert to oxidative environment (Fig. S5), samples synthesized up to $350{ }^{\circ} \mathrm{C}$ do not show any change in TGA trend, implying their complete degradation during TG analysis in inert atmosphere. On the contrary, PhCN400 sample exhibits a different behavior, showing an abrupt loss mass. This is consistent with the formation of a certain amount of chair content, which commonly occurs for higher molecular weight compounds [33].

To have a more detailed understanding of the process, a TGA measurement coupled with in-line FT-IR was performed on Ph-Triazine. The thermal treatment performed was selected to simulate the synthesis procedure (Fig. 3b), collecting IR spectra of the volatilized compounds. The heat map reported in Fig. 3c demonstrate the appearance of IR peaks mainly at two wavenumbers: about $3750 \mathrm{~cm}^{-1}$ and about $1500 \mathrm{~cm}^{-1}$. A clearer analysis could be performed analyzing representative peaks selected at different stages of the process (Fig. 3d).

At low temperature $\left(0\right.$ s i.e. $20^{\circ} \mathrm{C}$ and 60 s i.e. $\left.50^{\circ} \mathrm{C}\right)$ no peaks were observed, which is related to the fact that no volatile compounds were evolved. Increasing the temperature (spectra at 500 s, i.e. $270^{\circ} \mathrm{C}$ ), absorption at $1540 \mathrm{~cm}^{-1}$ (triazine ring) is observed, indicating the begin of the volatilization of the starting material. Furtherly increasing the temperature (spectra at 700 s, i.e. $350^{\circ} \mathrm{C}$ ), the gas species present a spectrum close to phenyl triazine, indicating that all the species are volatized and available for gas phase reaction [34]. This is clearer in the spectra collected during the isothermal step (spectra at 2500 s), in which a new large band centered at $1690 \mathrm{~cm}^{-1}$ is visible. This is compatible with the formation of aromatic adducts close to triazine ring, confirming the formation of polymerized structures [34].

\subsubsection{Differential Scanning Calorimetry measurements}

By DSC measurements, we retrieved melting temperatures $\left(\mathrm{T}_{\mathrm{m}}\right)$ and glass transition $\left(\mathrm{T}_{\mathrm{g}}\right.$ ) temperatures of all the samples (Table 1 and Fig. S6).

$\mathrm{Ph}$-Triazine shows a clear melting temperature at $233^{\circ} \mathrm{C}$; this value is slightly higher than the reported $\mathrm{T}_{\mathrm{m}}\left(220^{\circ} \mathrm{C}\right)$, however this could be related to the heating rate which may shift melting to higher temperatures. Similarly, PhCN300 sample shows a single melting peak at a slightly lower temperature than Ph-Triazine $\left(230^{\circ} \mathrm{C}\right)$. This is in good agreement with XRD spectra, which show a similar crystalline structure, even if at lower extent; as a further confirmation, a decrease of enthalpy peak was observed. This trend is more evident in PhCN350, with a further decrease of both $\mathrm{T}_{\mathrm{m}}$ and peak area. Interestingly, in this sample appears a $\mathrm{T}_{g}$ at $105^{\circ} \mathrm{C}$. This amorphous area could be explained once again taking into consideration the increase of molecular weight in the structures by increasing the temperature of thermal treatment. In fact, the higher the molecular weight, the lower the mobility of the macromolecules, which could lead to have amorphous region. This could clearly be observed in PhCN400 samples, which do not present 
a)

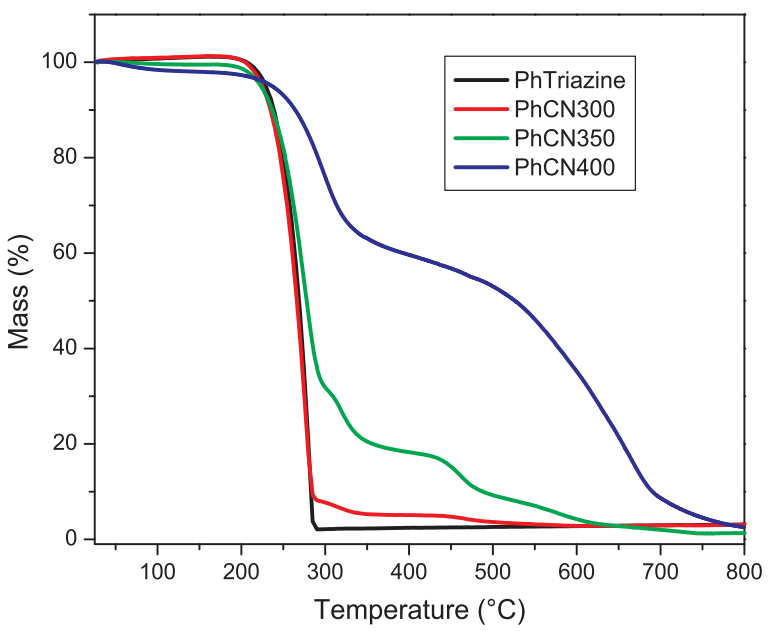

c)

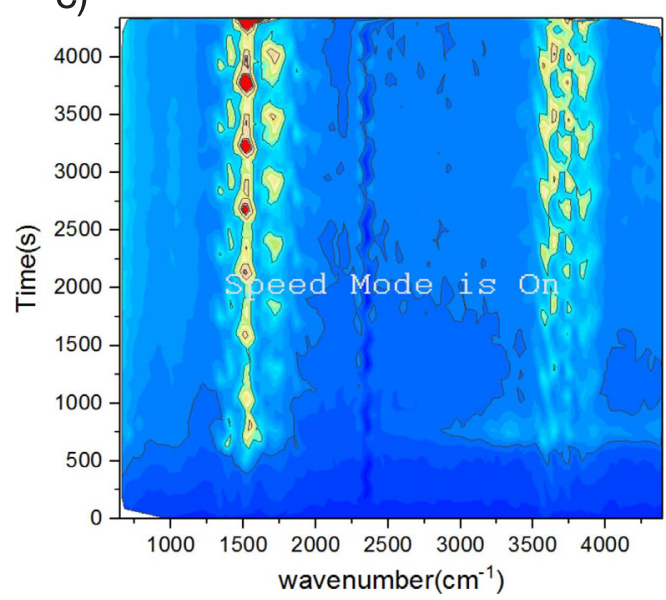

b)

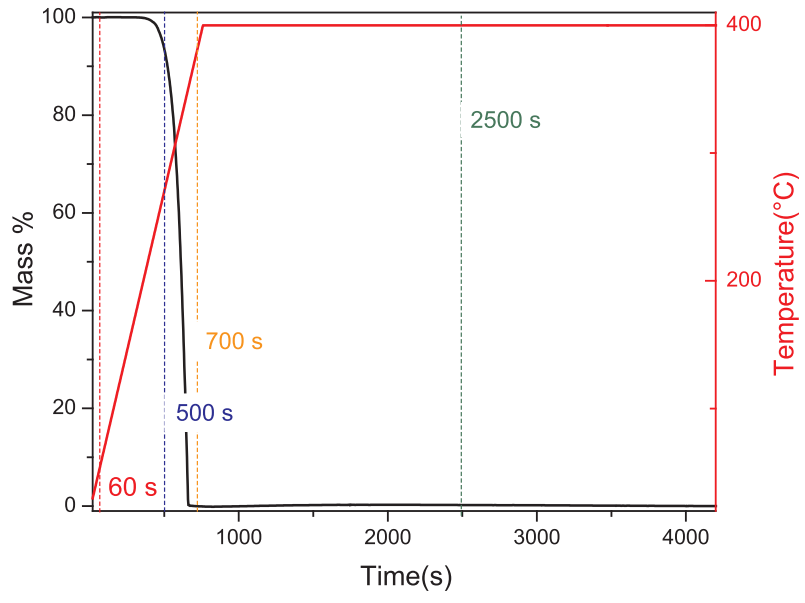

d)

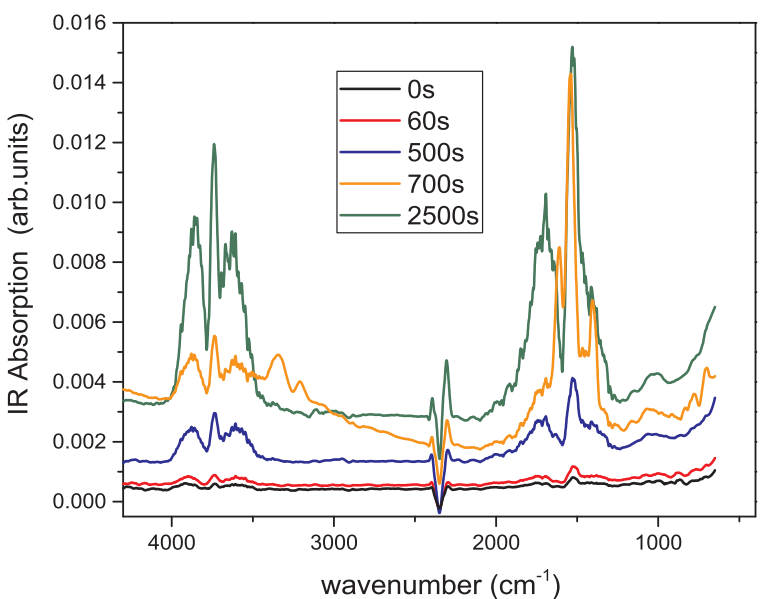

Fig. 3. TGA curves for the temperature treated samples (a). Thermal curve and relative weight loss (b). The heat map in panel (c) report the evolution of the FTIR spectra registered during the thermal curve. Representative FTIR spectra acquired at different time during the thermal curve (d).

Table 1

DSC parameters of PhTriazine and samples prepared at $300,350,400{ }^{\circ} \mathrm{C}$. Melting temperatures (Tm), glass transition ( $\mathrm{Tg}$ ) temperatures and enthalpy change of thermal transitions per unit weight of sample $(\Delta \mathrm{H})$.

\begin{tabular}{llll}
\hline Sample & $\operatorname{Tm}\left({ }^{\circ} \mathrm{C}\right)$ & $\operatorname{Tg}\left({ }^{\circ} \mathrm{C}\right)$ & $\Delta \mathrm{H}(\mathrm{W} / \mathrm{g})$ \\
\hline PhTriazine & 233 & - & -22.4 \\
PhCN $300{ }^{\circ} \mathrm{C}$ & 230 & - & -20.9 \\
PhCN $350{ }^{\circ} \mathrm{C}$ & 221 & 105 & -9.7 \\
PhCN $400{ }^{\circ} \mathrm{C}$ & - & 115 & \\
\hline
\end{tabular}

any melting peak but a clear $\mathrm{T}_{\mathrm{g}}$ at $115^{\circ} \mathrm{C}$, which means that the powder is mainly amorphous. This is in good agreement with the observed formation of heptazine structures, which present low mobility due to the large extent of conjugated structures, not allowing the formation of long-range crystal organization. The polymerization scheme in function of the temperature is reported in Fig. 4.

\subsection{Optical characterization}

\subsubsection{UV-Vis measurements}

The presence of the phenyl group in the carbon nitride structure allows to decrease the absorption bandgap. Indeed, the mixing of $\pi / \pi^{*}$ interactions of phenyl group for LUMO and LUMO' results in a symmetry matching that allows the transitions from HOMO/HOMO' to LUMO/LUMO', forbidden in the pure g- $_{3} \mathrm{~N}_{4}$ structure [35]. On this view, the number and the position of the phenyl groups has obvious consequence on the main optical properties of the compound. Fig. 5a shows the optical absorption in the UV-visible range of the samples treated at different temperatures, evidencing the different behavior of the samples. A progressive redshift of the optical absorption maxima is clearly visible as the treating temperature is increased.

The absorption spectrum of the starting material exhibits its main maximum at $320 \mathrm{~nm}$ (Fig. 5b).

The increase of the annealing temperature at $250{ }^{\circ} \mathrm{C}$ results in a slight broadening of the absorption edge towards higher wavelengths. The sample prepared at $300{ }^{\circ} \mathrm{C}$ presents a steady increase of the absorption in the $350-550 \mathrm{~nm}$ region, whilst keeping relatively unchanged the main absorption band at the higher energy. The sample prepared at $350^{\circ} \mathrm{C}$ exhibits a further increase of the absorption in the visible region of the spectrum, showing two additional maxima at 350 and $433 \mathrm{~nm}$, respectively. Finally, the sample prepared at $400{ }^{\circ} \mathrm{C} \mathrm{ex}$ hibits a broad band with the absorption edge red shifted up to $450 \mathrm{~nm}$.

The optical bandgaps of the CN products were calculated according to the Tauc plots $\left((\alpha h \nu)^{1 / 2}\right.$ versus $h \nu$, in which $\alpha$ is the diffuse absorption coefficient, $\mathrm{h}$ is the Planck constant, and $\nu$ is the light frequency). As reported in Fig. S7 of the supporting material, the bandgap of the starting material and PhCN250 is estimated at about $3.55 \mathrm{eV}$ 


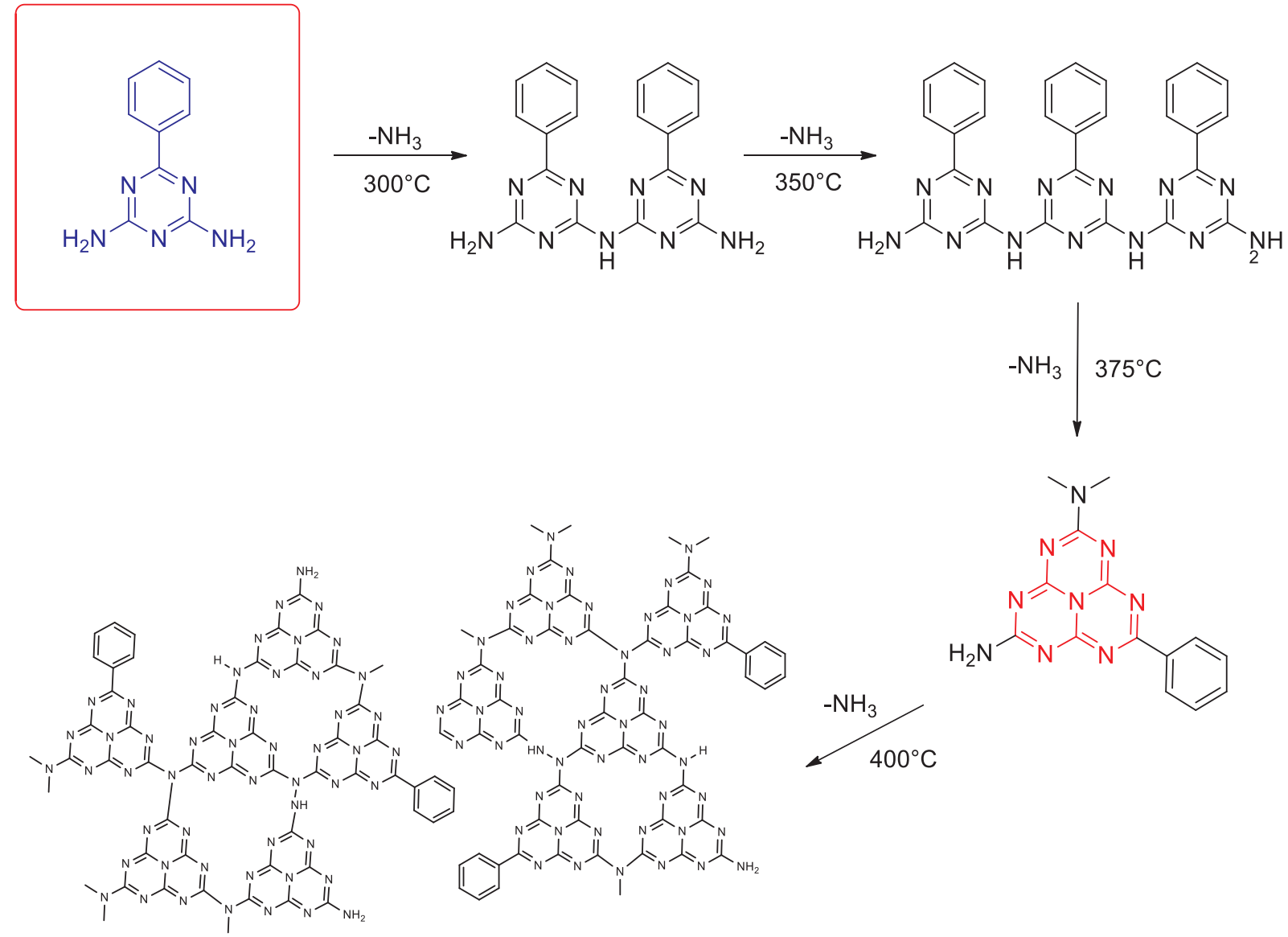

Fig. 4. Polymerization scheme of 6-phenyl-1,3,5-triazine-2,4-diamine.
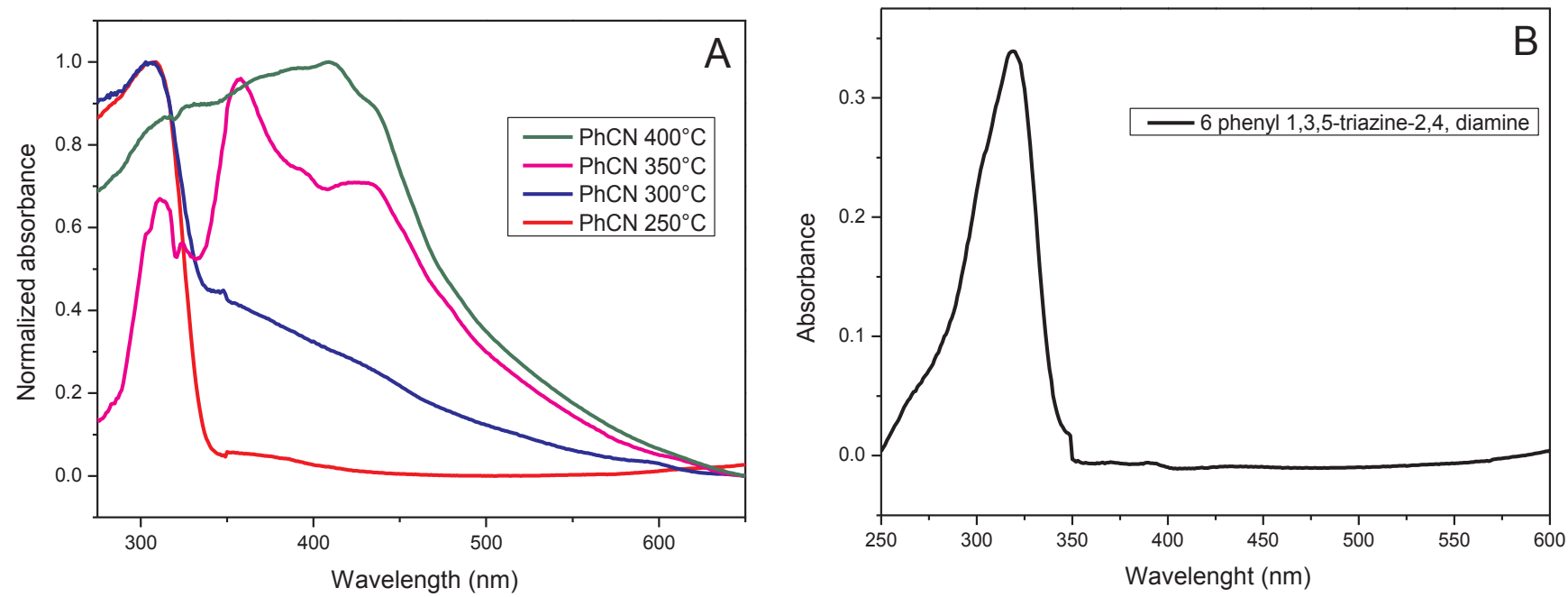

Fig. 5. (a) Absorption spectra of the samples prepared at different temperatures. (b) Absorption spectrum of 6-phenyl-1,3,5-triazine-2,4-diamine.

(350 nm). The samples PhCN300 and 350 show the evidence of multiple absorption edges, indicating that the product is constituted by different polymorphs, as already indicated in the HMRS analysis, with bandgap at about 3.2 and $2.1 \mathrm{eV}$ (387 and $590 \mathrm{~nm}$ ), respectively. Finally, the absorption onset of the sample PhCN400 presents a clear rise with a bandgap at about $2.0 \mathrm{eV}(620 \mathrm{~nm})$. It is worth to note that there is no general agreement in the literature on phenyl modified Carbon Nitride concerning the bandgap, values in the $2.8-2.4 \mathrm{eV}$ being reported, suggesting that different structures were possibly obtained depending on the synthesis properties.

\subsubsection{Steady State Luminescence measurements}

Fig. S8 reports the steady state luminescence spectra of the compounds obtained at different temperatures, showing a progressive redshift of the emissions as the temperature increases. In the framework of different polymorphs synthesized as a function of the increasing temperature, the reported emission redshift should be interpreted in terms of the conjugation length of the $\pi$ system. It was already pointed out that the aromatic molecules can be easily modelled as a particle, where the optical electron is confined in the aromatic ring system representing a linear box [36]. In this approximation of a quantum model, as the box 

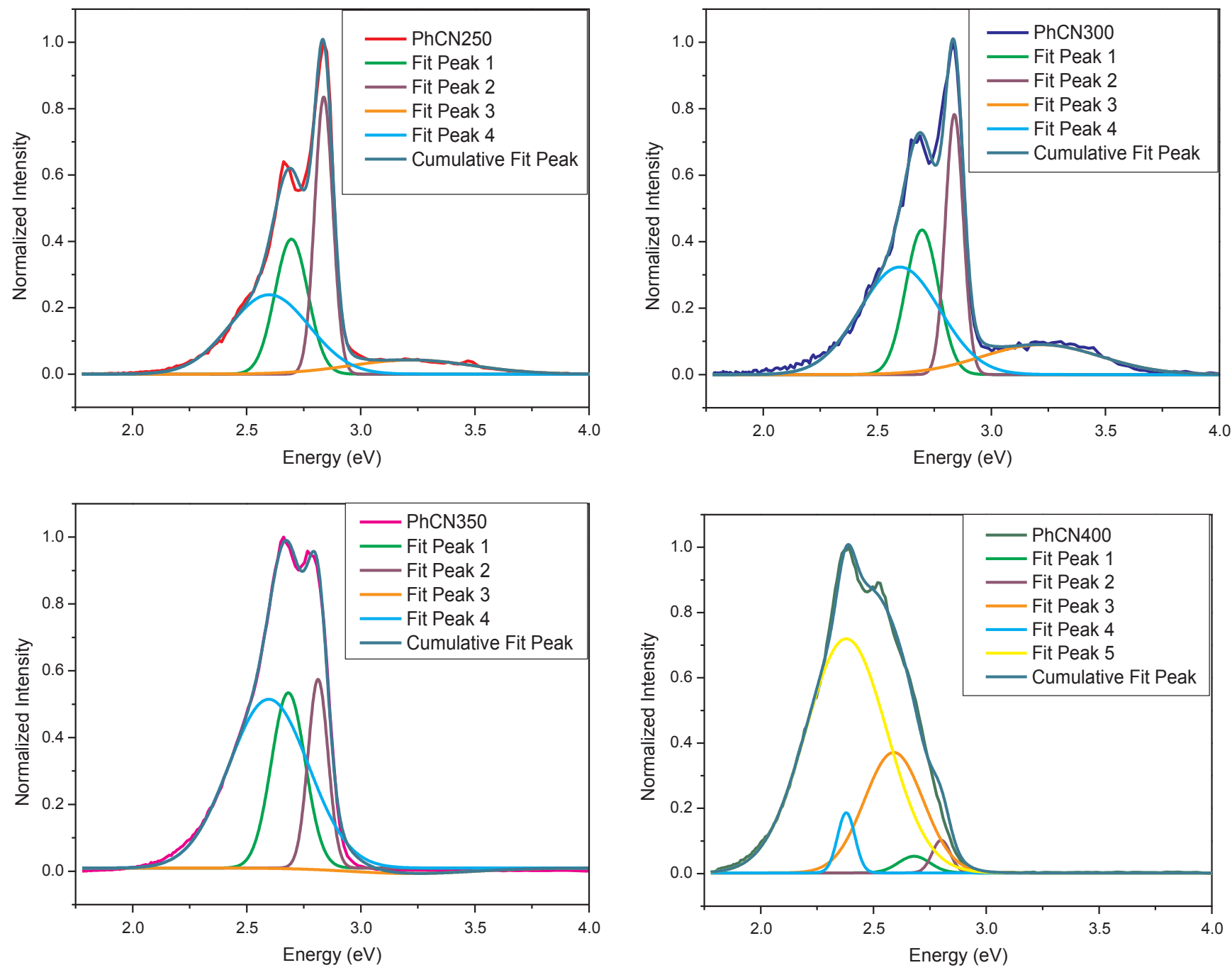

Fig. 6. Gaussian fitting of the PL spectra of the samples prepared at $250,300,350$ and $400{ }^{\circ} \mathrm{C}$ respectively.

dimension increases the energy separation between highest occupied and lowest unoccupied orbitals decreases. Accordingly, an increase of the conjugation length of the $\pi$ system generates a shift of the emission spectra towards the longer wavelength [36], in good agreement with the reported emission spectra. To outline the contribution of the possible different polymorphs, the emission spectra were analyzed by means of Gaussian bands in the energy space; each band represents a specific radiative channel of recombination, whose relative integrated intensity is related to the contribution of the different species in the samples (Fig. 6).

All the spectra were successfully deconvoluted with 3 or 4 Gaussian bands, whose spectral features are summed up in Table 2 .

Taking into account the three levels scheme and the different electronic states in Carbon Nitride systems, $\left(\mathrm{sp}^{3} \mathrm{C}-\mathrm{N} \sigma\right.$ band, $\mathrm{sp}^{2} \mathrm{C}-\mathrm{N} \pi$ band and the lone pair state of the bridging nitrogen atom), three main recombination channels are recognized: from $\sigma^{*}$ to LP, from $\pi^{*}$ to LP and from $\pi^{*}$ to $\pi[17,35]$. The emission bands extracted by the fitting procedure can be associated to these transitions (Fig. 7).

It is worth to note that the contribution of the higher energy band progressively decreases by increasing the temperature of synthesis, whilst the one of the large bands at lower energy increases, two more bands are required to fit the large emission at low energy for the sample cured at $400{ }^{\circ} \mathrm{C}$. Indeed, as the conjugation length increases, the contribution from the $\pi$ level increases with a progressive depletion of the $\sigma$ level due to non-radiative energy transfer to the $\pi$ levels. Thus, the high energy contribution is reduced and the one at lower energy is increased because of the increase of the reaction degree with increasing curing temperature [37].

Table 2

Gaussian fit results of samples: PhCN250, PhCN300, PhCN350 and PhCN400 as obtained in Fig. 5.

\begin{tabular}{|c|c|c|c|c|c|c|c|c|c|c|c|c|c|c|c|}
\hline \multirow[t]{2}{*}{ Sample } & \multicolumn{3}{|l|}{ Band 1} & \multicolumn{3}{|l|}{ Band 2} & \multicolumn{3}{|l|}{ Band 3} & \multicolumn{3}{|l|}{ Band 4} & \multicolumn{3}{|l|}{ Band 5} \\
\hline & $\mathrm{Xc}(\mathrm{eV})$ & FWHM & Area & $\mathrm{Xc}(\mathrm{eV})$ & FWHM & Area & $\mathrm{Xc}(\mathrm{eV})$ & FWHM & Area & $\mathrm{Xc}(\mathrm{eV})$ & FWHM & Area & $\mathrm{Xc}(\mathrm{eV})$ & FWHM & Area \\
\hline PhCN250 & 3.22 & 0.62 & 0.28 & 2.83 & 0.09 & 0.083 & 2.69 & 0.17 & 0.073 & 2.56 & 0.41 & 0.010 & - & - & - \\
\hline PhCN300 & 3.22 & 0.61 & 0.06 & 2.83 & 0.09 & 0.076 & 2.69 & 0.17 & 0.078 & 2.58 & 0.412 & 0.142 & - & - & - \\
\hline PhCN350 & - & - & - & 2.81 & 0.10 & 0.06 & 2.68 & 0.17 & 0.09 & 2.59 & 0.412 & 0.22 & - & - & - \\
\hline PhCN400 & - & - & - & 2.81 & 0.09 & 0.01 & 2.68 & 0.17 & 0.01 & 2.59 & 0.30 & 0.12 & 2.38 & 0.42 & 0.324 \\
\hline
\end{tabular}




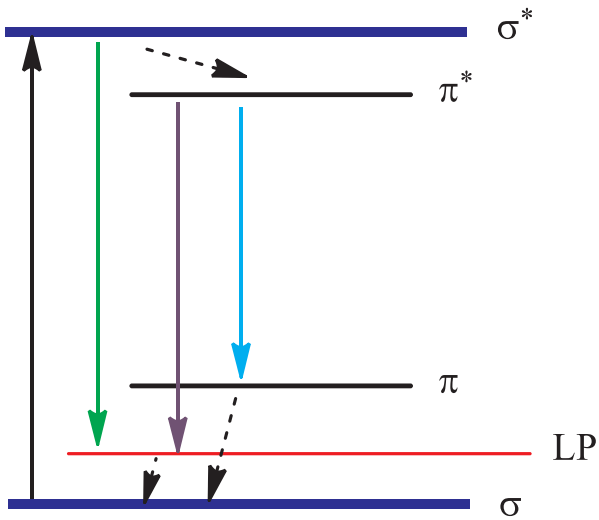

Fig. 7. Energy levels scheme in PhCN polymorphs.

\subsubsection{Time resolved measurements}

To further characterize the optical properties of PhCN samples we performed time resolved measurements exciting at $350 \mathrm{~nm}$ (well above the optical bandgap of all the samples) and analyzing the decay time profiles with a multiexponential decay function, [38]

$\mathrm{y}=\mathrm{y}_{0}+\sum_{\mathrm{i}} \mathrm{A}_{\mathrm{i}} \mathrm{e}^{-\frac{\mathrm{t}}{\tau_{\mathrm{i}}}}$

Fit results are presented in Fig. 8, and the retrieved decay parameters are presented in Table 3 .
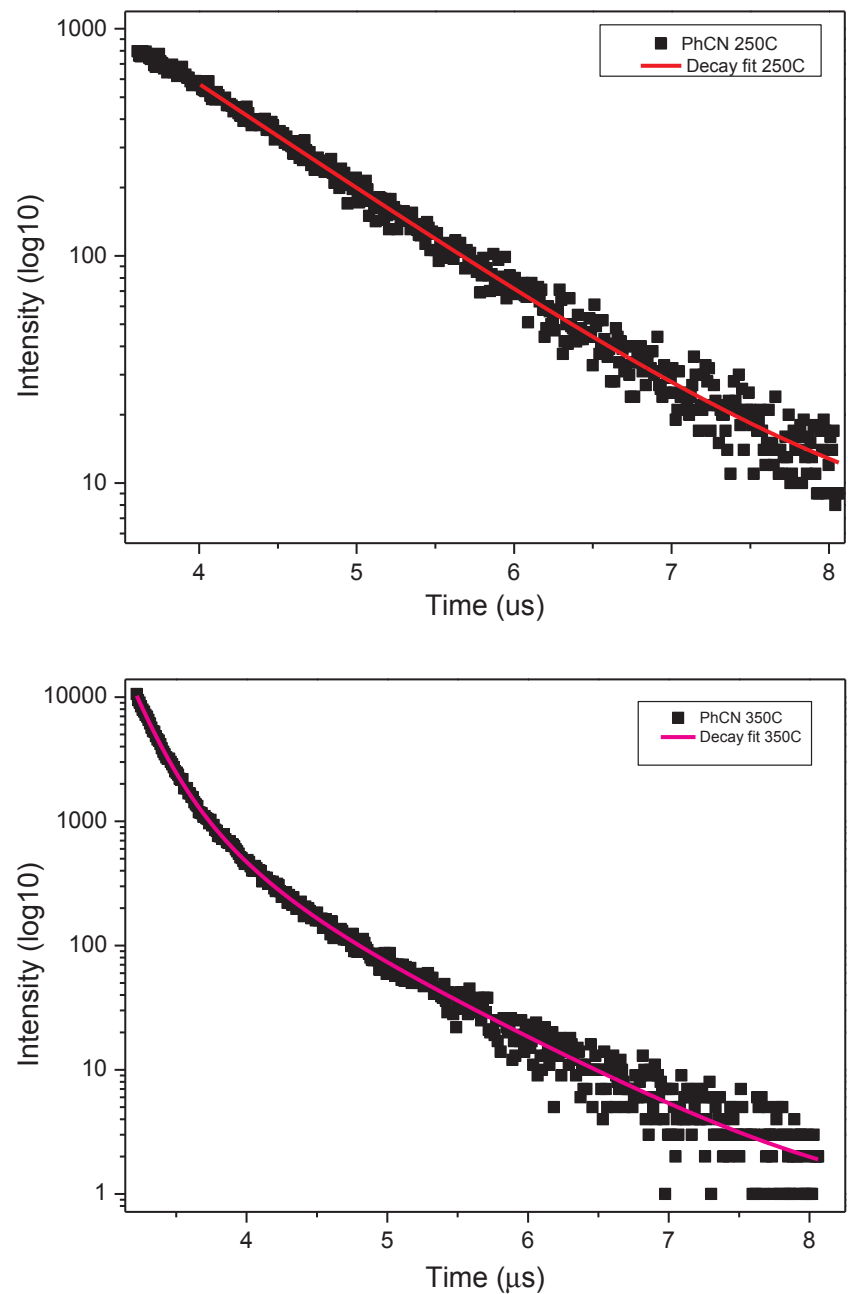

Table 3

Time parameters obtained from fits in Fig. 8.

\begin{tabular}{lllllll}
\hline Sample & A1 & t1 $(\mu \mathrm{s})$ & A2 & t2 $(\mu \mathrm{s})$ & A3 & t3 $(\mu \mathrm{s})$ \\
\hline PhCN250 & 562.3 & 0.935 & - & - & - & - \\
PhCN300 & 529.7 & 0.999 & 3810.4 & 0.425 & - & - \\
PhCN350 & 501 & 0.901 & 4695 & 0.173 & - & - \\
PhCN400 & 43.6 & 0.745 & 809.91 & 0.151 & 2676.53 & 0.03667
\end{tabular}

Different time behaviors are observed depending on the thermal treatment. In general, as the curing temperature increases the time profile appears faster and more complicated. Sample cured at lower temperature presents single, very slow recombination channel, with lifetime of almost $1 \mathrm{~ms}(\tau=0.935 \mathrm{~ms})$. By increasing the curing temperature, the decay shortens, and two new faster components are required to successfully fit the time profile, with lifetime of $425 \mathrm{~ns}$ and $173 \mathrm{~ns}$ for the PhCN300 and PhCN350 samples, respectively. The time profile of the sample treated at $400{ }^{\circ} \mathrm{C}(\mathrm{PhCN} 400)$ is even faster, with a very small contribution in the microsecond region and two decays at 151 and $36 \mathrm{~ns}$. This is a further indication that the synthesis conditions modify both the structure and the optical features of Phenyl modified g$\mathrm{C}_{3} \mathrm{~N}_{4}$ compounds, time and spectral tunability being achieved by different thermal treatments. In addition, due to the large red shift of PhCN400 sample, we measured the decay time by exciting in the visible region (at $410 \mathrm{~nm}$, but still above its bandgap). The time decay and the spectral profile seem to be not affected by the variation of the excitation
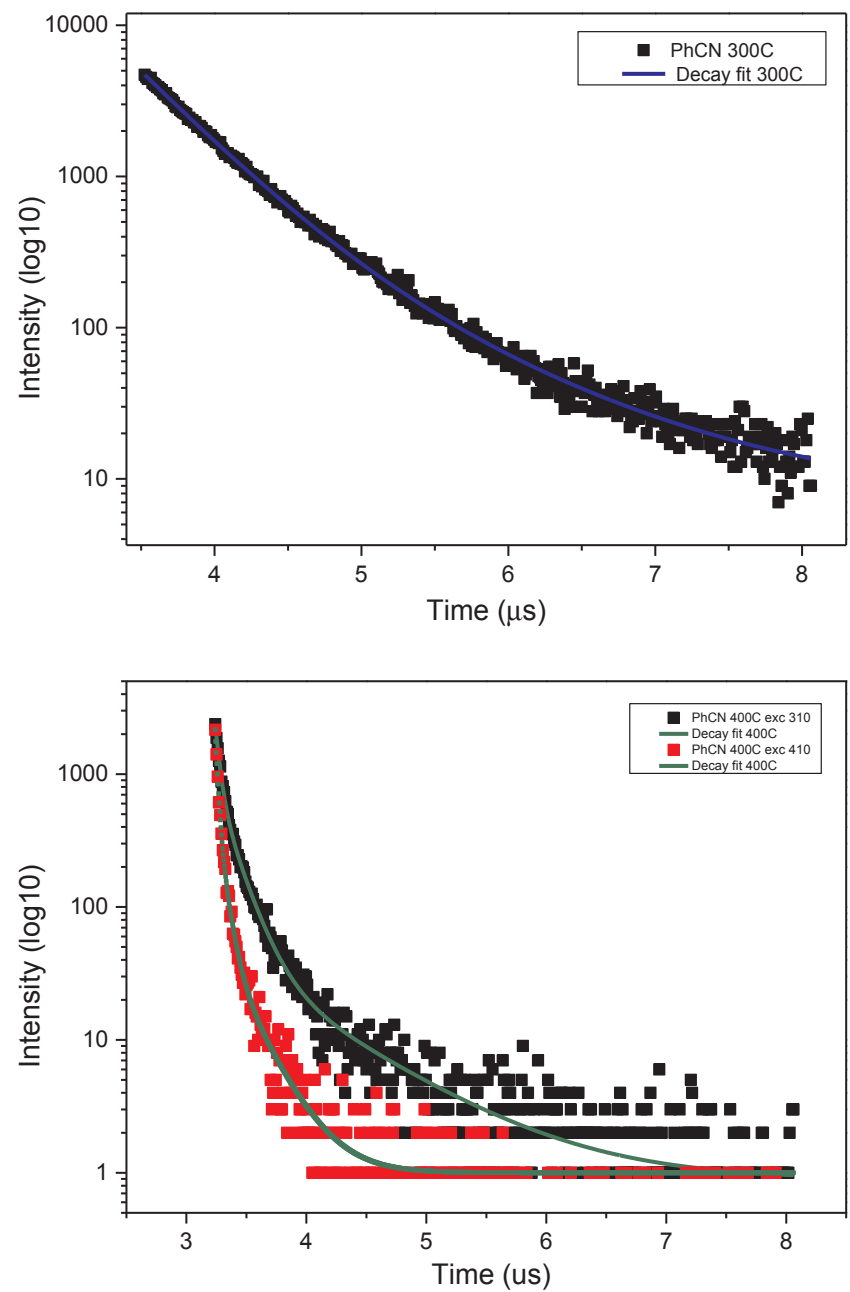

Fig. 8. Time decay photoluminescence fits of PhCN250, PhCN300, PhCN350 samples with a 310 nm excitation wavelength and PhCN $400{ }^{\circ} \mathrm{C}$ sample with a 310 and $410 \mathrm{~nm}$ excitation wavelength, acquired over a $5 \mu$ s time window. 
a)

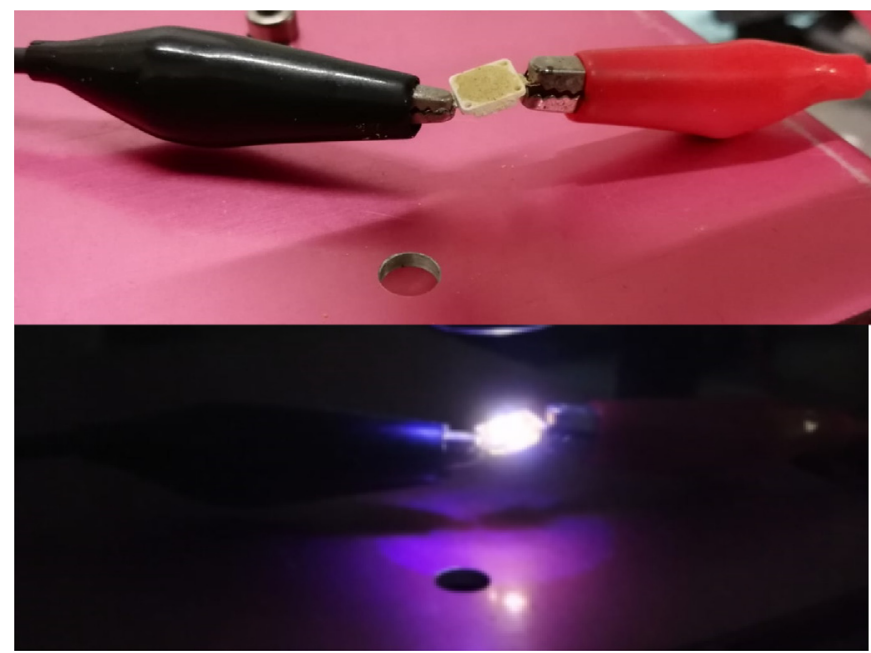

b)

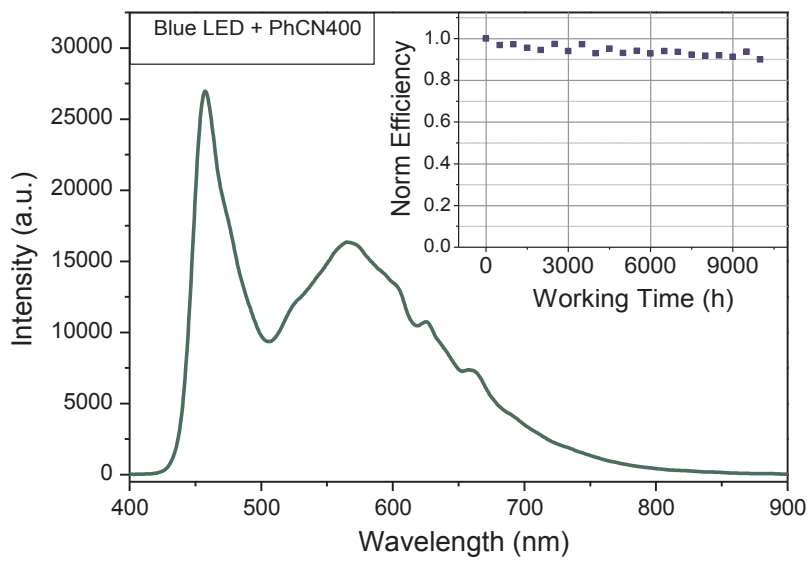

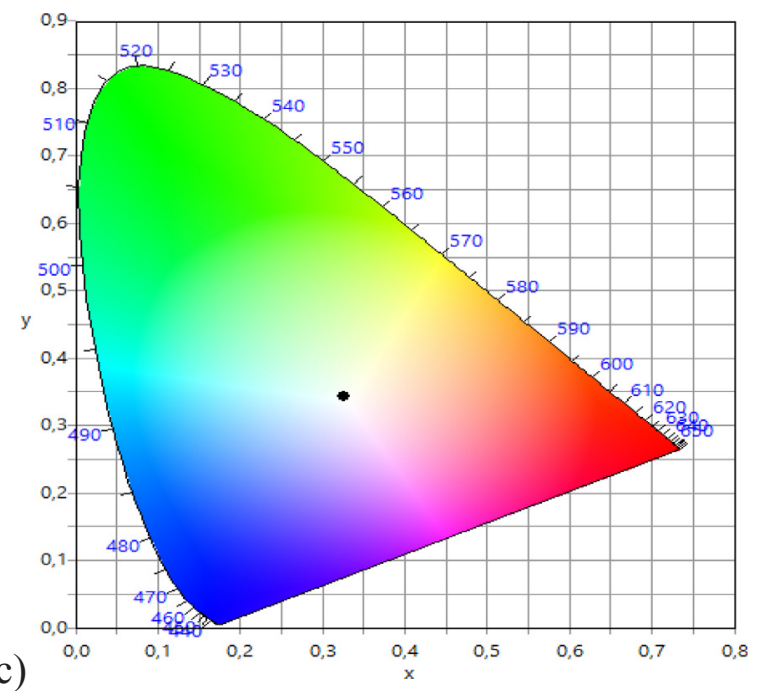

Fig. 9. (a) Prototype of a White LED. (b) Steady state luminescence spectrum of prototype. (c) CIE. The inset in the panel B reports the overall emission registered for continuously working time regime.

wavelength. The time spectral profiles were acquired over two different time range, $100 \mathrm{~ns}$ and $2 \mathrm{~ms}$ (Fig. S9), to enlighten possible different contributions to the overall emission spectrum. As evidenced, the spectral profile shows the presence of at least two contributions, one at high energy, characterized by a faster decay, and one at lower energy with a slower decay time. This trend resembles the decay kinetics of pure g- $\mathrm{C}_{3} \mathrm{~N}_{4}$, where two decay times were observed and related to the two excited levels $\left(\sigma^{*}\right.$ and $\left.\pi^{*}\right)[16,35]$. The recombination from the highest conduction level $\sigma^{*}$ is affected to a larger extent by non-radiative process related to the non-radiative interaction among planes and, hence, presents a faster decay time. However, the time scale of the recombination in the $\mathrm{g}-\mathrm{C}_{3} \mathrm{~N}_{4}$ (in the ns time domain) is very different with respect to the one of Phenyl modified $\mathrm{CN}$ compounds. In that case a very reduced emission efficiency with an estimated Quantum Yield (QY) of about 7\% is observed, because of the presence of non-radiative recombination channels between planes. On the contrary, the estimated QY of PhCN400 sample was of $62 \%$, and very similar values were measured for all the other samples (55\% for PhCN250, 51\% for PhCN300, and 57\% for PhCN350).

\section{Application}

The optical features above reported, and in particular the ones of the PhCN400 sample, promote PhCNs as good phosphors for white LED (WLED) applications. White light in LED is generally achieved by combing the monochromatic emission of a pumping LED (generally chosen at about $450 \mathrm{~nm}$, as a good compromise between short wavelength emission and eye sensitivity) with a broad emission in the green to red spectral region (500-650 nm) of a suitable phosphor. Research of new phosphors is very active and partially driven by the necessity to substitute Ce:YAG, because of its low Color Rendering Index, and the high supply disruption of Rare Earth Elements [1]. The optical properties of PhCN400 match very well the excitation and the emission requirements for WLED applications, coupled with high quantum efficiency and fast decays to avoid saturation effect. In addition, a high structural and thermal stability is required, since the phosphor is located close to the LED chip and only approximately $80 \%$ of the input power is converted to optical power; the remaining power produces instead heat to be dissipated by the device. Given the small chip area and the limited phosphor area, temperatures from $100{ }^{\circ} \mathrm{C}$ up to $200{ }^{\circ} \mathrm{C}$ can be easily reached close to the chip, thus the thermal resistance up to $400{ }^{\circ} \mathrm{C}$ of PhCN compounds is a very boosting feature for these organic compounds that can be prepared by a very facile and low-cost synthesis procedure. For this reason, a first prototype of a WLED was realized, with the combination of a blue LED (Golden Dragon Osram) with the main emission at $465 \mathrm{~nm}$, with the PhCN400 compound deposited in 
close contact with the junction (Fig. 9a). The amount of the organic compound was set to partially transmit the emission from the pumping LED and to use the absorbed light to generate the broad emission in the $500-650 \mathrm{~nm}$ spectral range (Fig. 9b). The prototype generates an overall emission (LED + phosphor) with CIE coordinates of $x=0.3256$ and $y=0.3437$ for an optimal white color, associated to a Color Rendering Index of 88. (Fig. 9c). The prototype was tested setting the current at $250 \mathrm{~mA}$ and monitoring the emission for about $10,000 \mathrm{~h}$ (inset panel 9b). The spectral shape remained almost stable in that period and the emission intensity remains stable above $90 \%$ with respect to the starting one.

\section{Conclusions}

The correlation between structural and optical properties in phenyl modified g- $\mathrm{C}_{3} \mathrm{~N}_{4}$ was analyzed. Different structures were observed as a function of the temperature in the thermal solid-state reaction of the starting material (6-phenyl-1,3,5-triazine-2,4-diamine powder). Firstly, the formation of dimer/trimer conjugated triazine units were observed with subsequently, the formation of the heptazine structure and, finally, the formation of the $\mathrm{g}-\mathrm{C}_{3} \mathrm{~N}_{4}$-like structures. A progressive red shift of the main optical features (absorption/emission) were observed as the conjugation increases.

The optimal sample for lighting application was identified in the phenyl modified $\mathrm{g}-\mathrm{C}_{3} \mathrm{~N}_{4}$ sample, obtained with thermal treatment at $400{ }^{\circ} \mathrm{C}$, that presents the optical absorption tail at $450 \mathrm{~nm}$ and a broad, emission in the green-red part of the visible range. These features, associated with high internal quantum yield (above 60\%), and high thermal and flux stability, were proven suitable for efficient white LED emission.

Finally, the similarity in the structure of the sample with the $g-\mathrm{C}_{3} \mathrm{~N}_{4}$ but for the optical absorption shifted in the visible range, strongly suggests an easy achievable way to tune and control the properties of such polymorphs for other applications, like photocatalysis.

\section{Declaration of Competing Interest}

The authors declare that they have no known competing financial interests or personal relationships that could have appeared to influence the work reported in this paper.

\section{Appendix A. Supplementary material}

Supplementary data to this article can be found online at https:// doi.org/10.1016/j.apsusc.2019.144330.

\section{References}

[1] Ec, Annexes to the report on critical raw materials for the Eu, 2014

[2] D. Chiriu, L. Stagi, C.M. Carbonaro, R. Corpino, M.F. Casula, P.C. Ricci, Towards the development of new phosphors with reduced content of rare earth elements: structural and optical characterization of Ce:Tb: Al2SiO5, Mater. Res. Bull. 77 (2016) 15-22, https://doi.org/10.1016/j.materresbull.2016.01.011.

[3] C.M. Carbonaro, D. Chiriu, P.C. Ricci, Are organic compounds good candidates to substitute rare earth materials in fluorescent applications? Phys. Status Solidi Curr. Top. Solid State Phys. 13 (2016), https://doi.org/10.1002/pssc.201600130.

[4] F.A. Viola, A. Spanu, P.C. Ricci, A. Bonfiglio, P. Cosseddu, Ultrathin, flexible and multimodal tactile sensors based on organic field-effect transistors, Sci. Rep. 8 (2018), https://doi.org/10.1038/s41598-018-26263-1.

[5] A. Spanu, F. Viola, S. Lai, P. Cosseddu, P.C. Ricci, A. Bonfiglio, A reference-less pH sensor based on an organic field effect transistor with tunable sensitivity, Org. Electron. Phys., Mater. Appl. 48 (2017), https://doi.org/10.1016/j.orgel.2017.06. 010

[6] Y. Cui, H. Yao, J. Zhang, T. Zhang, Y. Wang, L. Hong, K. Xian, B. Xu, S. Zhang, J. Peng, Z. Wei, F. Gao, J. Hou, Over 16\% efficiency organic photovoltaic cells enabled by a chlorinated acceptor with increased open-circuit voltages, Nat Commun. 10 (2019) 2515, https://doi.org/10.1038/s41467-019-10351-5.

[7] W. Ong, L. Tan, Y.H. Ng, S. Yong, S. Chai, Graphitic carbon nitride (g-C3N4) - Based photocatalysts for artificial photosynthesis and environmental remediation: are we a step closer to achieving sustainability?, (2016). doi:10.1021/acs.chemrev. $6 \mathrm{~b} 00075$
[8] T.R. Chetia, M.S. Ansari, M. Qureshi, Graphitic carbon nitride as a photovoltaic booster in quantum dot sensitized solar cells: a synergistic approach for enhanced charge separation and injection, J. Mater. Chem. A. 4 (2016) 5528-5541, https:// doi.org/10.1039/c6ta00761a.

[9] H. Guo, J. Zhang, L. Ma, J.L. Chavez, L. Yin, H. Gao, Z. Tang, W. Chen, A non-rareearth ions self-activated white emitting phosphor under single excitation, Adv. Funct. Mater. 25 (2015) 6833-6838, https://doi.org/10.1002/adfm.201502641.

[10] A. Wang, C. Lee, H. Bian, Z. Li, Y. Zhan, J. He, Y. Wang, J. Lu, Y.Y. Li, Synthesis of gC3N4/silica gels for white-light-emitting devices, Part. Part. Syst. Charact. 34 (2017) 1-5, https://doi.org/10.1002/ppsc.201600258.

[11] F. Yang, M. Lublow, S. Orthmann, C. Merschjann, T. Tyborski, M. Rusu, S. Kubala, A. Thomas, R. Arrigo, M. Hävecker, T. Schedel-Niedrig, Metal-free photocatalytic graphitic carbon nitride on p-type chalcopyrite as a composite photocathode for light-induced hydrogen evolution, ChemSusChem 5 (2012) 1227-1232, https://doi. org $/ 10.1002 /$ cssc. 201100691

[12] X. Li, K. Xie, L. Song, M. Zhao, Z. Zhang, Enhanced photocarrier separation in hierarchical graphitic-C3N4-supported CuInS2 for noble-metal-free Z-scheme photocatalytic water splitting, ACS Appl. Mater. Interfaces 9 (2017) 24577-24583, https://doi.org/10.1021/acsami.7b06030

[13] M. Bledowski, L. Wang, A. Ramakrishnan, O.V. Khavryuchenko, V.D. Khavryuchenko, P.C. Ricci, J. Strunk, T. Cremer, C. Kolbeck, R. Beranek, Visible-light photocurrent response of TiO2-polyheptazine hybrids: evidence for interfacial charge-transfer absorption, Phys. Chem. Chem. Phys. 13 (2011) 21511, https://doi.org/10.1039/c1cp22861g.

[14] A.T. Montoya, E.G. Gillan, Photocatalytic carbon nitride materials with nanoscale features synthesized from the rapid and low-temperature decomposition of trichloromelamine, ACS Appl. Nano Mater. 1 (2018) 5944-5956, https://doi.org/10. 1021/acsanm.8b01670.

[15] S.C. Yan, Z.S. Li, Z.G. Zou, Photodegradation performance of g-C3N4 fabricated by directly heating, Melamine 25 (2009) 11269-11273, https://doi.org/10.1021/ la900923z.

[16] L. Stagi, D. Chiriu, C.M. Carbonaro, R. Corpino, P.C. Ricci, Structural and optical properties of carbon nitride polymorphs, Diam. Relat. Mater. 68 (2016) 84-92, https://doi.org/10.1016/j.diamond.2016.06.009.

[17] Q. Cui, J. Xu, X. Wang, L. Li, M. Antonietti, M. Shalom, Phenyl-modified carbon nitride quantum dots with distinct photoluminescence behavior, Angew. Chemie Int. Ed. 55 (2016) 3672-3676, https://doi.org/10.1002/anie.201511217.

[18] Z. Song, Z. Li, L. Lin, Y. Zhang, T. Lin, L. Chen, Z. Cai, S. Lin, L. Guo, F. Fu, X. Wang, Phenyl-doped graphitic carbon nitride: Photoluminescence mechanism and latent fingerprint imaging, Nanoscale 9 (2017) 17737-17742, https://doi.org/10.1039/ c7nr04845a.

[19] T. Chen, C. Chen, Q. Liu, Z. Zhang, X. Fang, A one-step process for preparing a phenyl-modified g-C3N4 green phosphor with a high quantum yield, RSC Adv. 7 (2017) 51702-51710, https://doi.org/10.1039/c7ra09873a.

[20] B.X. Wang, X. Chen, A. Thomas, X. Fu, M. Antonietti, metal-containing carbon nitride compounds: a new functional organic - metal hybrid material, (2009) 1609-1612. doi:10.1002/adma.200802627.

[21] X. Chen, J. Zhang, X. Fu, M. Antonietti, X. Wang, Fe-g-C3N4 -catalyzed oxidation of benzene to phenol using hydrogen peroxide and visible, Light (2009) 11658-11659.

[22] H. Xu, J. Yan, Y. Xu, Y. Song, H. Li, J. Xia, C. Huang, Novel visible-light-driven AgX / graphite-like C3N4 (X = Br, I) hybrid materials with synergistic photocatalytic activity, Appl. Catal. B, Environ. 129 (2013) 182-193, https://doi.org/10.1016/j. apcatb.2012.08.015

[23] P.C. Ricci, N. Laidani, D. Chiriu, M. Salis, C.M. Carbonaro, R. Corpino, ALD growth of metal oxide on carbon nitride polymorphs, Appl. Surf. Sci. 456 (2018) 83-94, https://doi.org/10.1016/j.apsusc.2018.06.021.

[24] J. Sun, R. Phatake, A. Azoulay, G. Peng, C. Han, J. Barrio, J. Xu, X. Wang, M. Shalom, Covalent functionalization of carbon nitride frameworks through crosscoupling reactions, Chem. - A Eur. J. 24 (2018) 14921-14927, https://doi.org/10. 1002/chem.201803201.

[25] T. Lin, Z. Song, Y. Wu, L. Chen, S. Wang, F. Fu, L. Guo, Boron- and phenyl-codoped graphitic carbon nitride with greatly enhanced light responsive range for photocatalytic disinfection, J. Hazard. Mater. 358 (2018) 62-68, https://doi.org/10. 1016/j.jhazmat.2018.06.053.

[26] W. Zhang, J. Albero, L. Xi, K.M. Lange, H. Garcia, X. Wang, M. Shalom, One-pot synthesis of nickel-modified carbon nitride layers toward efficient photoelectrochemical cells, ACS Appl. Mater. Interfaces 9 (2017) 32667-32677, https://doi. org/10.1021/acsami.7b08022.

[27] G. Algara-siller, N. Severin, S.Y. Chong, T. Bjçrkman, R.G. Palgrave, A. Laybourn, M. Antonietti, Y.Z. Khimyak, A.V Krasheninnikov, J.P. Rabe, U. Kaiser, A.I. Cooper, A. Thomas, M.J. Bojdys, Triazine-based graphitic carbon nitride: a two- dimensional semiconductor (2014) 7450-7455. doi:10.1002/anie.201402191.

[28] T. Tyborski, C. Merschjann, S. Orthmann, F. Yang, M.-C. Lux-Steiner, T. SchedelNiedrig, Crystal structure of polymeric carbon nitride and the determination of its process-temperature-induced modifications, J. Phys. Condens. Matter. 25 (2013) 395402, , https://doi.org/10.1088/0953-8984/25/39/395402.

[29] B. Jürgens, E. Irran, J. Senker, P. Kroll, H. Müller, W. Schnick, Melem (2,5,8-triamino-tri-s-triazine), an important intermediate during condensation of melamine rings to graphitic carbon nitride: synthesis, structure determination by $\mathrm{x}$-ray powder diffractometry, solid-state NMR, and theoretical studies, J. Am. Chem. Soc. 125 (2003) 10288-10300, https://doi.org/10.1021/ja0357689.

[30] C. Merschjann, S. Tschierlei, T. Tyborski, K. Kailasam, S. Orthmann, D. Hollmann, T. Schedel-niedrig, A. Thomas, S. Lochbrunner, Complementing graphenes: 1D interplanar charge transport in polymeric graphitic carbon, Nitrides (2015) 7993-7999, https://doi.org/10.1002/adma.201503448.

[31] L. Stagi, D. Chiriu, M. Scholz, C.M. Carbonaro, R. Corpino, A. Porcheddu, 
S. Rajamaki, G. Cappellini, R. Cardia, P.C. Ricci, Vibrational and optical characterization of s-triazine derivatives, Spectrochim. Acta - Part A Mol. Biomol. Spectrosc. 183 (2017), https://doi.org/10.1016/j.saa.2017.04.053.

[32] M.A. Mohamed, M.F.M. Zain, L. Jeffery Minggu, M.B. Kassim, N.A. Saidina Amin, W.N.W. Salleh, M.N.I. Salehmin, M.F. Md Nasir, Z.A. Mohd, Hir, Constructing biotemplated 3D porous microtubular C-doped g-C3N4 with tunable band structure and enhanced charge carrier separation, Appl. Catal. B Environ. 236 (2018) 265-279, https://doi.org/10.1016/j.apcatb.2018.05.037.

[33] C.A. Wilkie, TGA/FTIR: an extremely useful technique for studying polymer degradation, 66 (1999) 301-306.

[34] J.D. Loughran, G.A. Ehlers, G.F.L. Crawford, W.J. Burkett, J.L. Ray, The infrared spectra of some new derivatives of S-triazine, Appl. Spectrosc. 18 (1994) 129-134, https://doi.org/10.1366/000370264789620420.

35] Yuanhao Zhang, Qiwen Pan, Guanqi Chai, Minru Liang, Guoping Dong,

Qinyuan Zhang, Jianrong Qiu, Synthesis and luminescence mechanism of multicolor-emitting g-C3N4 nanopowders by low temperature thermal condensation of melamine, Sci. Rep. 3 (1) (2013), https://doi.org/10.1038/srep01943.

[36] Y. Yamaguchi, Y. Matsubara, T. Ochi, T. Wakamiya, Z. Yoshida, How the $\pi$ conjugation length affects the fluorescence emission efficiency (2008) 13867-13869.

[37] D. Das, S.L. Shinde, K.K. Nanda, Temperature-Dependent Photoluminescence of $\mathrm{g}$ C3N4: implication for Temperature Sensing, ACS Appl. Mater. Interfaces. 8 (2016) 2181-2186, https://doi.org/10.1021/acsami.5b10770.

[38] Lakowicz, Principles of Fluorescence Spectroscopy, III, Springer, Boston, 1983. 